
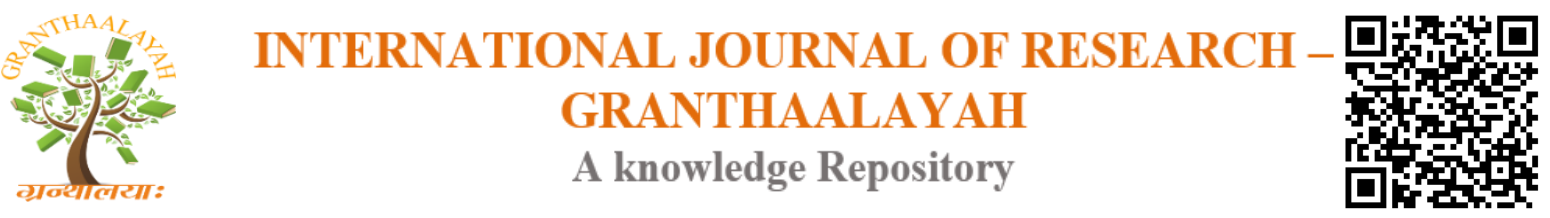

Science

\title{
AMPLIFIED NELDER-MEAD ALGORITHM FOR SOLVING OPTIMAL REACTIVE POWER PROBLEM
}

\author{
Dr. K. Lenin *1 \\ ${ }^{* 1}$ Professor, Prasad V. Potluri Siddhartha Institute of Technology, Kanuru, Vijayawada, Andhra \\ Pradesh -520007, India
}

\begin{abstract}
This paper presents Hybridization of Simulated Annealing with Nelder-Mead algorithm (SN) is proposed to solve optimal reactive power problem. The proposed Hybridized - Simulated Annealing, Nelder-Mead algorithm starts with a prime solution, which is produced arbitrarily and then the solution is disturbed into partitions. The vicinity zone is created, arbitrary numbers of partitions are selected and variables modernizing procedure is started in order to create a trail of neighbour solutions. This procedure helps the SN algorithm to explore the region around an existing iterate solution. The Nelder- Mead algorithm is used in the last stage in order to progress the most excellent solution found so far and hasten the convergence in the closing stage. The proposed Hybridization of Simulated Annealing with Nelder-Mead algorithm (SN) has been tested in standard IEEE 57,118 bus systems and simulation results show the superior performance of the proposed SN algorithm in reducing the real power loss and voltage profiles are within the limits.
\end{abstract}

Keywords: Nelder-Mead Algorithm; Simulated Annealing; Optimal Reactive Power; Transmission Loss.

Cite This Article: Dr. K. Lenin. (2018). “AMPLIFIED NELDER-MEAD ALGORITHM FOR SOLVING OPTIMAL REACTIVE POWER PROBLEM.” International Journal of Research Granthaalayah, 6(11), 299-306. https://doi.org/10.29121/granthaalayah.v6.i11.2018.1131.

\section{Introduction}

Optimal reactive power dispatch problem is one of the difficult optimization problems in power systems. The sources of the reactive power are the generators, synchronous condensers, capacitors, static compensators and tap changing transformers. The problem that has to be solved in a reactive power optimization is to determine the required reactive generation at various locations so as to optimize the objective function. Here the reactive power dispatch problem involves best utilization of the existing generator bus voltage magnitudes, transformer tap setting and the output of reactive power sources so as to minimize the loss and to maintain voltage stability of the system. It involves a nonlinear optimization problem. Various mathematical techniques have been adopted to solve this optimal reactive power dispatch problem. These include the gradient method [1, 2], Newton method [3] and linear programming [4-7]. The gradient and Newton methods suffer from the 
difficulty in handling inequality constraints. To apply linear programming, the input- output function is to be expressed as a set of linear functions which may lead to loss of accuracy. Recently many global optimization techniques have been proposed to solve the reactive power flow problem [8-10]. This paper presents Hybridization of Simulated Annealing with Nelder-Mead algorithm (SN) is proposed to solve optimal reactive power problem. Simulated annealing (SA) had a major impact on the field of heuristic search for its simplicity and efficiency in solving combinatorial optimization problems [11-14]. The Nelder-Mead algorithm [15,16] is one of the most popular derivative free nonlinear optimization algorithms. The proposed Hybridized - Simulated Annealing, Nelder-Mead algorithm starts with a prime solution, which is produced arbitrarily and then the solution is disturbed into partitions. The vicinity zone is created, arbitrary numbers of partitions are selected and variables modernizing procedure is started in order to create a trail of neighbour solutions. This procedure helps the $\mathrm{SN}$ algorithm to explore the region around an existing iterate solution. The Nelder- Mead algorithm is used in the last stage in order to progress the most excellent solution found so far and hasten the convergence in the closing stage. The proposed Hybridization of Simulated Annealing with Nelder-Mead algorithm (SN) has been tested in standard IEEE 57,118 bus systems and simulation results show the superior performance of the proposed SN algorithm in reducing the real power loss and voltage profiles are within the limits.

\section{Objective Function}

\section{Active Power Loss}

The objective of the reactive power dispatch problem is to minimize the active power loss and can be written in equations as follows:

$\mathrm{F}=P_{L}=\sum_{\mathrm{k} \in \mathrm{Nbr}} \mathrm{g}_{\mathrm{k}}\left(\mathrm{V}_{\mathrm{i}}^{2}+\mathrm{V}_{\mathrm{j}}^{2}-2 \mathrm{~V}_{\mathrm{i}} \mathrm{V}_{\mathrm{j}} \cos \theta_{\mathrm{ij}}\right)$

Where F- objective function, $\mathrm{P}_{\mathrm{L}}$ - power loss, $\mathrm{g}_{\mathrm{k}}$ - conductance of branch, $\mathrm{V}_{\mathrm{i}}$ and $\mathrm{V}_{\mathrm{j}}$ are voltages at buses i,j, Nbr- total number of transmission lines in power systems.

\section{Voltage Profile Improvement}

To minimize the voltage deviation in PQ buses, the objective function $(\mathrm{F})$ can be written as:

$\mathrm{F}=P_{L}+\omega_{\mathrm{v}} \times \mathrm{VD}$

Where VD - voltage deviation, $\omega_{\mathrm{v}^{-}}$is a weighting factor of voltage deviation.

And the Voltage deviation given by:

$$
\mathrm{VD}=\sum_{\mathrm{i}=1}^{\mathrm{Npq}}\left|\mathrm{V}_{\mathrm{i}}-1\right|
$$

Where Npq- number of load buses

\section{Equality Constraint}

The equality constraint of the problem is indicated by the power balance equation as follows:

$$
\mathrm{P}_{\mathrm{G}}=\mathrm{P}_{\mathrm{D}}+\mathrm{P}_{\mathrm{L}}
$$

Where $\mathrm{P}_{\mathrm{G}^{-}}$total power generation, $\mathrm{P}_{\mathrm{D}}$ - total power demand. 


\section{Inequality Constraints}

The inequality constraint implies the limits on components in the power system in addition to the limits created to make sure system security. Upper and lower bounds on the active power of slack bus $\left(\mathrm{P}_{\mathrm{g}}\right)$, and reactive power of generators $\left(\mathrm{Q}_{\mathrm{g}}\right)$ are written as follows:

$$
\begin{gathered}
\mathrm{P}_{\text {gslack }}^{\text {min }} \leq \mathrm{P}_{\text {gslack }} \leq \mathrm{P}_{\text {gslack }}^{\text {max }} \\
\mathrm{Q}_{\mathrm{gi}}^{\min } \leq \mathrm{Q}_{\mathrm{gi}} \leq \mathrm{Q}_{\mathrm{gi}}^{\max }, \mathrm{i} \in \mathrm{N}_{\mathrm{g}}
\end{gathered}
$$

Upper and lower bounds on the bus voltage magnitudes $\left(\mathrm{V}_{\mathrm{i}}\right)$ is given by:

$$
\mathrm{V}_{\mathrm{i}}^{\min } \leq \mathrm{V}_{\mathrm{i}} \leq \mathrm{V}_{\mathrm{i}}^{\max }, \mathrm{i} \in \mathrm{N}
$$

Upper and lower bounds on the transformers tap ratios $\left(\mathrm{T}_{\mathrm{i}}\right)$ is given by:

$$
\mathrm{T}_{\mathrm{i}}^{\min } \leq \mathrm{T}_{\mathrm{i}} \leq \mathrm{T}_{\mathrm{i}}^{\max }, \mathrm{i} \in \mathrm{N}_{\mathrm{T}}
$$

Upper and lower bounds on the compensators $\left(Q_{c}\right)$ is given by:

$$
\mathrm{Q}_{\mathrm{c}}^{\min } \leq \mathrm{Q}_{\mathrm{c}} \leq \mathrm{Q}_{\mathrm{C}}^{\max }, \mathrm{i} \in \mathrm{N}_{\mathrm{C}}
$$

Where $\mathrm{N}$ is the total number of buses, $\mathrm{N}_{\mathrm{g}}$ is the total number of generators, $\mathrm{N}_{\mathrm{T}}$ is the total number of Transformers, $\mathrm{N}_{\mathrm{c}}$ is the total number of shunt reactive compensators.

\section{Simulated Annealing}

The SA algorithm is a probabilistic hill-climbing technique that is based on the annealing/cooling process of metals. This annealing process occurs after the heat source is removed from a molten metal and its temperature starts to decrease. At each temperature level the energy of the metal molecules reduces and the metal becomes more rigid. The procedure continues until the metal temperature has reached the surrounding ambient temperature, at which stage the energy has reached its lowest value and the metal is perfectly solid. The SA procedure begins by generating an initial solution at random. At initial stages, a small random change is made in the current solution $\mathrm{X}_{\mathrm{c}}$. The new solution is called $\mathrm{X}_{\mathrm{n}}$. The perturbation depends on a temperate parameter $T$, and a scaling constant $\mathrm{k}$.

$\operatorname{pert}(T)=k \times T \times r_{3}$

Here $r_{3}$ is a random value between 0 and 1 with uniform distribution. The temperature $T$ decreases with each iteration of the algorithm, thus reducing the size of the perturbations as the search progresses. This mechanism produces large perturbation in the initial stages of the search and ensures that the resulting parameters are fine-tuned towards the end of the optimization. A move is made to the new solution $\mathrm{X}_{\mathrm{n}}$ if it has better energy $F$ or if the probability function has a higher value than a randomly generated number. Otherwise a new solution is generated, evaluated and compared again. The probability $p$ of accepting a new solution $\mathrm{X}_{\mathrm{n}}$ which called "Metropolis law" is given as follows: 
$P=\left\{\begin{array}{rr}1 & \text { if } F\left(X_{n}\right)<F\left(X_{c}\right) \\ & \exp \left(\frac{F\left(X_{c}\right)-F\left(X_{n}\right)}{T}\right) \text { otherwise }\end{array}\right.$

In order to avoid getting trapped at local extreme points, the reduction rate of $T$ should be slow enough. In this study the following method to reduce the temperature has been used. Here $T_{0}$ is the initial temperature, $\beta$ is the reduction constant, and $n$ is the number of iterations.

\section{Nelder-Mead Algorithm}

Nelder-Mead algorithm is one of the most popular derivative free nonlinear optimization algorithms. The Nelder-Mead algorithm starts with $n+1$ point (vertices) as $x 1, x 2, \ldots, x n+1$. The algorithm evaluates order and re-labels the vertices. At each iteration, new points are computed, along with their function values, to form a new simplex. Four scalar parameters must be specified to define a complete Nelder-Mead algorithm; coefficients of reflection $\rho$, expansion $\chi$, contraction $\gamma$, and shrinkage $\sigma$. These parameters are chosen to satisfy $\rho>0, \chi>1,0<\gamma<1$ and $0<\sigma<1$.

\section{Hybridization of Simulated Annealing with Nelder-Mead Algorithm}

The projected Hybridization of Simulated Annealing with Nelder-Mead algorithm (SN) starts with a primary solution generated arbitrarily, which consists of $n$ variables. The solution is divided into $\eta$ partitions; each partition contains $v$ variables. At a fixed temperature, arbitrary partitions are selected, and trail solutions are produced by updating arbitrary numbers of variables in the selected partition. The neighbour solution with the best objective function value is always acknowledged. Else, the neighbour is selected with a given probability that depends on the current temperature and the amount of deprivation $\Delta \mathrm{E}$ of the objective value. $\Delta \mathrm{E}$ represents the difference in the objective value between the current solution and produced neighbouring solution. At a particular level of temperature, many trails solutions are explored until the equipoise state is reached, which is a given number of iterations executed at each temperature $\mathrm{T}$ in our in $\mathrm{SN}$ algorithm. The temperature is progressively decreased according to a cooling schedule. The consequence is repeated until $\mathrm{T}$ reached to $\mathrm{T}_{\min }$. $\mathrm{SN}$ uses the Nelder-Mead algorithm as a local search algorithm in order to refine the best solution found so far. Hybridization of Simulated Annealing with NelderMead algorithm (SN) starts with an initial solution $\mathrm{x}^{0}$ produced arbitrarily. At each iteration the solution is divided into $\eta$ partitions. The neighbourhood zone is produced in order to generate trail neighbourhood solutions. The produced neighbour solution that improves the objective function is always selected. Else the solution is accepted with a given probability e- $\Delta \mathrm{E} / \mathrm{T}$, where $\mathrm{T}$ is the current temperature, and $\Delta \mathrm{E}$ is the amount of the degradation of the objective function. The consequence is repeated until the equipoise state is reached. In SN algorithm, the equipoise state is a given number of iterations executed at each temperature, this number is equals to and $\mu$ is a user predefined number. Once the equilibrium state is reached, the temperature is diminished gradually according to a cooling schedule. This procedure is repeated until the stopping criteria satisfied, which is in our algorithm $\mathrm{T} \leq \mathrm{T}_{\min }$. In order to refine the best solution, $\mathrm{SN}$ uses the NelderMead algorithm as a local search algorithm in the final stage.

Choose an preliminary solution $\mathrm{x}^{0}$.

Set prime values for $\mathrm{T}_{\max }, \mathrm{T}_{\min }, \beta, \mu, \mathrm{v}, \mathrm{z}_{0}$.

Set $\mathrm{z}=\mathrm{z}_{0}, \mathrm{~T}=\mathrm{T}_{\max }, \mathrm{x}=\mathrm{x}^{0}$.

Repeat

$\mathrm{k}:=0$. 
Repeat

Partition the solution $x$ into $\eta$ partitions, where $\eta=n / v$.

Create neighbourhood trail solutions $\mathrm{y}^{1}, \ldots \mathrm{y}^{\mathrm{n}}$ around $\mathrm{x}$.

Set $\mathrm{x}^{\prime}$ equal to the best trail solution from $\mathrm{y}^{1}, \ldots \mathrm{y}^{\mathrm{n}}$.

$\Delta \mathrm{E}=\mathrm{f}\left(\mathrm{x}^{\prime}\right)-\mathrm{f}(\mathrm{x}) ;$ If $\Delta \mathrm{E} \leq 0$ then $\mathrm{x}=\mathrm{x}^{\prime}$.

$\mathrm{Z}=\tau \mathrm{Z}_{\max }, \tau>1$

Else

$\mathrm{z}=\alpha \mathrm{Z}_{\min }, \alpha<1$

If rand ()$<\mathrm{e}-{ }^{\Delta \mathrm{E} / \mathrm{T}}$ then $\mathrm{x}=\mathrm{x}^{\prime}$.

End If

End If

$\mathrm{k}=\mathrm{k}+1$.

Until $\mathrm{k} \leq \mu ; \mathrm{T}=\mathrm{T}-\beta$.

Until $\mathrm{T} \leq \mathrm{T}$ min; Apply Nelder-Mead algorithm at $\mathrm{N}_{\text {elite }}$ solutions.

\section{Simulation Results}

At first Proposed Hybridization of Simulated Annealing with Nelder-Mead algorithm (SN) has been tested in standard IEEE-57 bus power system. The reactive power compensation buses are 18, 25 and 53. Bus 2, 3, 6, 8, 9 and 12 are PV buses and bus 1 is selected as slack-bus. The system variable limits are given in Table 1.

The preliminary conditions for the IEEE-57 bus power system are given as follows:

$\mathrm{P}_{\text {load }}=12.012$ p.u. Q load $_{1}=3.016$ p.u.

The total initial generations and power losses are obtained as follows:

$\sum P_{G}=12.5041$ p.u. $\sum Q_{G}=3.3210$ p.u.

$P_{\text {loss }}=0.25620$ p.u. $Q_{\text {loss }}=-1.2012$ p.u.

Table 2 shows the various system control variables i.e. generator bus voltages, shunt capacitances and transformer tap settings obtained after SN based optimization which are within the acceptable limits. In Table 3, shows the comparison of optimum results obtained from proposed SN with other optimization techniques. These results indicate the robustness of proposed SN approach for providing better optimal solution in case of IEEE-57 bus system.

Table 1: Variable limits

\begin{tabular}{|c|c|c|c|c|c|c|c|c|c|}
\hline \multicolumn{10}{|c|}{ Reactive Power Generation Limits } \\
\hline Bus no & 1 & 2 & & 3 & 6 & 8 & & 9 & 12 \\
\hline Qgmin & -1.4 & -.0 & 15 & -.02 & -0.04 & -1 & & -0.03 & -0.4 \\
\hline Qgmax & 1 & 0.3 & & 0.4 & 0.21 & 1 & & 0.04 & 1.50 \\
\hline \multicolumn{10}{|c|}{ Voltage And Tap Setting Limits } \\
\hline vgmin & \multicolumn{2}{|c|}{ Vgmax } & \multicolumn{2}{|c|}{ vpqmin } & \multicolumn{2}{|c|}{ Vpqmax } & \multicolumn{2}{|c|}{ tkmin } & tkmax \\
\hline 0.9 & \multicolumn{2}{|c|}{1.0} & \multicolumn{2}{|c|}{0.91} & 1.05 & & \multicolumn{2}{|c|}{0.9} & 1.0 \\
\hline \multicolumn{7}{|c|}{ Shunt Capacitor Limits } & & & \\
\hline Bus no & \multicolumn{2}{|c|}{18} & \multicolumn{2}{|c|}{25} & \multicolumn{2}{|l|}{53} & & & \\
\hline Qcmin & \multicolumn{2}{|l|}{0} & \multicolumn{2}{|c|}{0} & \multicolumn{2}{|l|}{0} & & & \\
\hline Qcmax & \multicolumn{2}{|l|}{10} & \multicolumn{2}{|c|}{5.2} & \multicolumn{2}{|l|}{6.1} & & & \\
\hline
\end{tabular}


Table 2: Control variables obtained after optimization

\begin{tabular}{|l|l|}
\hline Control Variables & SN \\
\hline V1 & 1.1 \\
\hline V2 & 1.039 \\
\hline V3 & 1.042 \\
\hline V6 & 1.031 \\
\hline V8 & 1.034 \\
\hline V9 & 1.016 \\
\hline V12 & 1.028 \\
\hline Qc18 & 0.0650 \\
\hline Qc25 & 0.200 \\
\hline Qc53 & 0.0451 \\
\hline T4-18 & 1.010 \\
\hline T21-20 & 1.052 \\
\hline T24-25 & 0.875 \\
\hline T24-26 & 0.811 \\
\hline T7-29 & 1.052 \\
\hline T34-32 & 0.886 \\
\hline T11-41 & 1.020 \\
\hline T15-45 & 1.041 \\
\hline T14-46 & 0.910 \\
\hline T10-51 & 1.020 \\
\hline T13-49 & 1.060 \\
\hline T11-43 & 0.910 \\
\hline T40-56 & 0.900 \\
\hline T39-57 & 0.950 \\
\hline T9-55 & 0.950 \\
\hline & \\
\hline
\end{tabular}

Table 3: Comparison Results

\begin{tabular}{|l|l|l|l|l|}
\hline S.No. & Optimization Algorithm & Finest Solution & Poorest Solution & Normal Solution \\
\hline 1 & NLP [17] & 0.25902 & 0.30854 & 0.27858 \\
\hline 2 & CGA [17] & 0.25244 & 0.27507 & 0.26293 \\
\hline 3 & AGA [17] & 0.24564 & 0.26671 & 0.25127 \\
\hline 4 & PSO-w [17] & 0.24270 & 0.26152 & 0.24725 \\
\hline 5 & PSO-cf [17] & 0.24280 & 0.26032 & 0.24698 \\
\hline 6 & CLPSO [17] & 0.24515 & 0.24780 & 0.24673 \\
\hline 7 & SPSO-07 [17] & 0.24430 & 0.25457 & 0.24752 \\
\hline 8 & L-DE [17] & 0.27812 & 0.41909 & 0.33177 \\
\hline 9 & L-SACP-DE [17] & 0.27915 & 0.36978 & 0.31032 \\
\hline 10 & L-SaDE [17] & 0.24267 & 0.24391 & 0.24311 \\
\hline 11 & SOA [17] & 0.24265 & 0.24280 & 0.24270 \\
\hline 12 & LM [18] & 0.2484 & 0.2922 & 0.2641 \\
\hline 13 & MBEP1 [18] & 0.2474 & 0.2848 & 0.2643 \\
\hline 14 & MBEP2 [18] & 0.2482 & 0.283 & 0.2592 \\
\hline 15 & BES100 [18] & 0.2438 & 0.263 & 0.2541 \\
\hline
\end{tabular}




\begin{tabular}{|l|l|l|l|l|}
\hline 16 & BES200 [18] & 0.3417 & 0.2486 & 0.2443 \\
\hline 17 & Proposed SN & 0.22102 & 0.23154 & 0.22198 \\
\hline
\end{tabular}

Proposed Hybridization of Simulated Annealing with Nelder-Mead algorithm (SN) has been tested in standard IEEE 118-bus test system [19]. The system has 54 generator buses, 64 load buses, 186 branches and 9 of them are with the tap setting transformers. The limits of voltage on generator buses are 0.95-1.1 per-unit, and on load buses are 0.95-1.05 per-unit. The limit of transformer rate is $0.9-1.1$, with the changes step of 0.025 . The limitations of reactive power source are listed in Table 4, with the change in step of 0.01 .

Table 4: Limitation of reactive power sources

\begin{tabular}{|l|l|l|l|l|l|l|l|}
\hline BUS & 5 & 34 & 37 & 44 & 45 & 46 & 48 \\
\hline QCMAX & 0 & 14 & 0 & 10 & 10 & 10 & 15 \\
\hline QCMIN & -40 & 0 & -25 & 0 & 0 & 0 & 0 \\
\hline BUS & 74 & 79 & 82 & 83 & 105 & 107 & 110 \\
\hline QCMAX & 12 & 20 & 20 & 10 & 20 & 6 & 6 \\
\hline QCMIN & 0 & 0 & 0 & 0 & 0 & 0 & 0 \\
\hline
\end{tabular}

The statistical comparison results have been listed in Table 5 and the results clearly show the better performance of proposed SN algorithm.

Table 5: Comparison results

\begin{tabular}{|l|l|l|l|l|}
\hline Active power loss (MW) & $\begin{array}{l}\text { BBO } \\
{[\mathbf{2 0}]}\end{array}$ & $\begin{array}{l}\text { ILSBBO/ } \\
\text { strategy1 [20] }\end{array}$ & $\begin{array}{l}\text { ILSBBO/ } \\
\text { strategy1 [20] }\end{array}$ & $\begin{array}{l}\text { Proposed } \\
\text { SN }\end{array}$ \\
\hline Min & 128.77 & 126.98 & 124.78 & 116.02 \\
\hline Max & 132.64 & 137.34 & 132.39 & 122.86 \\
\hline Average & 130.21 & 130.37 & 129.22 & 118.74 \\
\hline
\end{tabular}

\section{Conclusion}

In this paper, Hybridization of Simulated Annealing with Nelder-Mead algorithm (SN) has been successfully solved the optimal reactive power problem. The proposed Hybridized - Simulated Annealing, Nelder-Mead algorithm starts with a prime solution, which is produced arbitrarily and then the solution is disturbed into partitions. The vicinity zone is created, arbitrary numbers of partitions are selected and variables modernizing procedure is started in order to create a trail of neighbour solutions. This procedure helps the SN algorithm to explore the region around an existing iterate solution. The Nelder- Mead algorithm is used in the last stage in order to progress the most excellent solution found so far and hasten the convergence in the closing stage. The proposed Hybridization of Simulated Annealing with Nelder-Mead algorithm (SN) has been tested in standard IEEE 57,118 bus systems and simulation results show the superior performance of the proposed $\mathrm{SN}$ algorithm in reducing the real power loss and voltage profiles are within the limits.

\section{References}

[1] O. Alsac, B. Scott, "Optimal load flow with steady state security", IEEE Transaction. PAS -1973, pp. 745-751. 
[2] Lee K Y, Paru Y M, Oritz J L -A united approach to optimal real and reactive power dispatch, IEEE Transactions on power Apparatus and systems 1985: PAS-104: 1147-1153

[3] Monticelli, M. V.F Pereira, and S. Granville, "Security constrained optimal power flow with post contingency corrective rescheduling", IEEE Transactions on Power Systems: PWRS-2, No. 1, pp.175-182.,1987.

[4] Deeb N, Shahidehpur S.M, Linear reactive power optimization in a large power network using the decomposition approach. IEEE Transactions on power system 1990: 5(2): 428-435

[5] E. Hobson,' Network consrained reactive power control using linear programming, 'IEEE Transactions on power systems PAS -99 (4), pp 868-877, 1980

[6] K.Y Lee, Y.M Park, and J.L Oritz, "Fuel -cost optimization for both real and reactive power dispatches", IEE Proc; 131C, (3), pp.85-93.

[7] M.K. Mangoli, and K.Y. Lee, "Optimal real and reactive power control using linear programming", Electr.Power Syst.Res, Vol.26, pp.1-10,1993.

[8] Berizzi. C. Bovo, M. Merlo, and M. Delfanti, (2012), "A GA approach to compare ORPF objective functions including secondary voltage regulation,” Electric Power Systems Research, vol. 84, no. 1, pp. $187-194$.

[9] D. Devaraj, and B. Yeganarayana, "Genetic algorithm based optimal power flow for security enhancement", IEE proc-Generation. Transmission and. Distribution; 152, 6 November 2005.

[10] C.A. Canizares, A.C.Z.de Souza and V.H. Quintana, "Comparison of performance indices for detection of proximity to voltage collapse," vol. 11. no.3, pp.1441-1450, Aug 1996.

[11] S. Kirkpatrick, C. Gelatt, M. Vecchi. "Optimization by simulated annealing", Science,220(4598):671-680, 1983. doi: 10.1016/s0736-5845(02)00013-3.

[12] V. Cerny. "A thermodynamical approach to the traveling salesman problem". An efficient simulation algorithm, Journal of Optimization Theory and Applications,45:41-51, 1985. doi: 10.1007/bf00940812.

[13] E. Cosola, K. Genovese, L. Lamberti, C. Pappalettere, A general framework for identification of hyper-elastic membranes with moiré techniques and multi-point simulated annealing, International Journal of Solids and Structures, 45 (2008) 6074-6099.

[14] E.W. McGookin, D.J. Murray-Smith, Submarine manoeuvring controllers' optimisation using simulated annealing and genetic algorithms, Control Engineering Practice, 14 (2006) 1-15.

[15] J. Nelder, R. Mead, " Asimplex method for function minimization", Computer journal, 7:308-313, 1965. doi: 10.1093/comjnl/7.4.308.

[16] Ahmed Fouad Ali , "Hybrid Simulated Annealing And Nelder-Mead Algorithm For Solving LargeScale Global Optimization Problems", International Journal of Research in Computer Science eISSN 2249-8265 Volume 4 Issue 3 (2014) pp. 1-11.

[17] Chaohua Dai, Weirong Chen, Yunfang Zhu, and Xuexia Zhang, "Seeker optimization algorithm for optimal reactive power dispatch," IEEE Trans. Power Systems, Vol. 24, No. 3, August 2009, pp. 1218-1231.

[18] J. R. Gomes and 0. R. Saavedra, "Optimal reactive power dispatch using evolutionary computation: Extended algorithms," IEE Proc.-Gener. Transm. Distrib.. Vol. 146, No. 6. Nov. 1999.

[19] IEEE, “The IEEE 30-bus test system and the IEEE 118-test system”, (1993), http://www.ee.washington.edu/trsearch/pstca/.

[20] Jiangtao Cao, Fuli Wang and Ping Li, "An Improved Biogeography-based Optimization Algorithm for Optimal Reactive Power Flow", International Journal of Control and Automation Vol.7, No.3 (2014), pp.161-176.

\footnotetext{
*Corresponding author.

E-mail address: gklenin@ gmail.com
} 